\title{
CFD PREDICTIONS OF N+3 CYCLE EMISSIONS FOR A THREE-CUP GAS-TURBINE COMBUSTOR
}

\author{
Kumud Ajmani \\ Vantage Partners, LLC \\ Cleveland, Ohio, USA \\ Hukam Mongia \\ CSTI Associates, LLC \\ Yardley, Pennsylvania, USA
}

\author{
Phil Lee \\ Woodward FST, Inc \\ Zeeland, MI, USA \\ Kathleen C. Tacina \\ NASA Glenn Research Center \\ Cleveland, Ohio, USA
}

\begin{abstract}
The National Combustion Code (OpenNCC) was used to perform non-reacting and two-phase reacting flow computations for a unique pre-filming type LDI-3 fuel injector for a three-cup, nineteen-element flametube configuration. All computations were performed with a consistent approach of mesh-generation, spray modeling, reduced finite-rate kinetics and turbulence-chemistry interaction, as developed for CFD analysis of single-element and multielement LDI-3 designs with OpenNCC. Emissions and flowfield characteristics were predicted for a generic NASA $\mathrm{N}+3$ engine cycle, with particular focus on the 7\% and 30\% ICAO power operating conditions. For both the conditions studied, the CFD analysis provided very good predictions for EINOx when compared with experimental data measured at NASA Glenn Research Center.
\end{abstract}

\subsection{INTRODUCTION}

NASA's N+3 aeronautics efforts under the Advanced Air Vehicles program set more stringent emissions and performance goals for gas-turbine systems for small-core engines [Ashcraft 2011] ${ }^{1}$. In addition, there is increased emphasis on design of fuel-flexible combustors [Hicks 2016] ${ }^{2}$ with drop-in fuels [Surgenor 2016] ${ }^{3}$. Some details of a third-generation multi-point Lean-Direct injection configuration (LDI-3) to meet NASA's N+3 goals were described in [Ajmani 2017] ${ }^{4}$. The new LDI-3 design is based on a combination of multi-element injection modules arranged in an annular array within the combustor. The three-cup design proposed by Woodward FST Inc consisted of three multielement modules (or cups) and leveraged several lessons learned from extensive experimental testing [Tacina 2016 $]^{5}$ and CFD evaluation [Ajmani 2014a] ${ }^{6}$ of previous generation N+2 research [Reddy 2016] ${ }^{7}$.

The primary goal of the efforts reported in this paper is to use OpenNCC CFD to compute the heat release and emissions (NOx and $\mathrm{CO}$ ) for a newly designed pre-filming fuel injection LDI-3 design proposed by Woodward FST, Inc. The current CFD effort follows several OpenNCC best-practice recommendations from the analysis performed for highpower (cruise) conditions for single-element and multi-element LDI-3 injector designs [Ajmani 2016] ${ }^{8}$. The CFD results presented here are for a three-cup (nineteen-element) flametube assembly based on an OpenNCC-optimized design of individual injection elements [Ajmani 2017] ${ }^{4}$. The focus of the current study is a CFD evaluation of the three-cup LDI-3 flametube for two engine cycle points (7\% and $30 \%$ power) of a generic NASA N+3 ICAO cycle.

Performance and emissions testing were performed for the three-cup LDI-3 flametube studied here at NASA Glenn Research Center (GRC). Experimental tests were performed for several N+3 cycle conditions, including cruise, $30 \%$ power and 7\% power. Testing of the three-cup assembly at NASA GRC's CE-5 facility had revealed some difficulties in establishing an appropriate fuel-staging for the current LDI-3 design for the $30 \%$ ICAO power condition. In addition, the combustion efficiency at the 7\% ICAO power condition, while deemed acceptable, was lower than expected [Tacina $2017]^{9}$. The current CFD analysis is motivated by a desire to gain a diagnostic understanding of the mixing performance and flow-field characteristics (flame shape, size, location) for the various injection elements of the three-cup LDI-3 assembly at these two operating conditions.

CFD computations with OpenNCC are reported for a generic NASA N+3 ICAO cycle that targets a single-aisle, mid-range aircraft of $25 \mathrm{Klb}$ thrust class at an operating pressure ratio of 40 at take-off. OpenNCC CFD results reported here will focus on flowfield predictions and emissions comparisons for the $7 \%$ power and 30\% ICAO power conditions. The CFD results obtained in this study are expected to provide inputs into the possible redesign of any injection elements in order to improve performance at $7 \%$ and $30 \%$ power conditions. A direct comparison with measured data (EINOx and EICO) will also be formed to evaluate OpenNCC's accuracy in predicting emissions at the conditions chosen for this study. The next few sections will describe computational approaches, details of the three-cup flametube hardware, and 
OpenNCC CFD results. The final section will provide a summary of the current work, and recommendations for future improvements in both the injector hardware and OpenNCC software tools.

\subsection{OPENNCC COMPUTATIONAL APPROACH AND METHODS}

OpenNCC is a state-of-the-art computational tool that is capable of solving the time-dependent, Navier-Stokes equations with chemical reactions. The software has been developed primarily at NASA GRC in order to support combustion simulations for a wide range of applications and has been extensively validated and tested for low-speed chemically reacting flows. Several 'best practices' for the use of OpenNCC for LDI injector design were achieved by extensive 'anchoring' [Ajmani 2013] ${ }^{10}$ with available LDI-1 data [Tacina 2005] ${ }^{11}$. The LDI-1 anchoring work enabled the use of OpenNCC in the evaluation of LDI-2 designs [Ajmani 2014a] ${ }^{6}$ (NASA N+2 program) and advanced CFD screening of LDI-3 designs [Ajmani 2016] ${ }^{7}$ (NASA N+3 program) at NASA GRC.

OpenNCC uses second-order accurate central-differences for the convective and diffusion flux discretization, and a Jameson operator (a blend of 2nd and 4th-order dissipation terms) for numerical stability. The second and fourth order dissipation parameters are typically set to $10^{-4}$ and 0.05 , respectively [Swanson 1997] ${ }^{12}$. The value of $\mathrm{k}_{2}$, the constant that scales the second order dissipation gradient switch, is typically set to 0.25 . In order to enhance convergence acceleration in pseudo-time, implicit residual smoothing is used to smooth the computed residuals in OpenNCC RANS. Turbulence closure is obtained with a two-equation, cubic k- $\varepsilon$ model with variable $\mathrm{C} \mu$ ([Shih 1998] ${ }^{13}$ ), and dynamic wall functions with pressure gradient effects ([Shih 2000] ${ }^{14}$ ).

Time-integration of the flow equations is typically initiated with steady-state, followed by a Time-Filtered NavierStokes/Very-Large Eddy-Simulation (TFNS) [Liu 2011] ${ }^{15}$ approach time-resolved solutions. In the TFNS approach, the filtered Navier-Stokes equations are established by applying a temporal filter to the exact form of the governing equations. The eddy viscosity contains a filtering-control parameter (FCP), which is defined as the ratio of a (conceptual) temporal filter width to a characteristic integral time scale of the turbulent flow. In practice, the content of the sub-filter turbulent kinetic energy is regulated by the (user-specified) FCP that is consistent with the mesh resolution. All the TFNS solutions presented in this paper use an FCP value of 0.3 . This value of FCP was established by studying the sensitivity of the timeaveraged, non-reacting flow TFNS solution for a chosen mesh resolution, following the process reported in [Ajmani $2013]^{10}$.

\subsection{Spray Modeling for Pre-filming (Main) and Simplex (Pilot) injectors}

The liquid spray (Jet-A fuel) was modeled by tracking spray particles in a Lagrangian framework, where each particle represents a group of actual spray droplets [Raju 2012] ${ }^{16}$. The governing equations for the liquid phase are based on a Lagrangian formulation where the spray particle position and velocity are described by a set of ordinary differential equations. The typical spray integration time-steps were 1e-7s (local time-step, $d t m l$ ) and 1e-6s (global time-step, dtgl), which is also the gas-phase physical time-step. In order to save computational time, spray particles were injected at every $10^{\text {th }}$ time-step (injection time-step, dtil). The droplet size distribution for injected particles was prescribed by the following correlation equation:

$$
\frac{\delta n}{n}=4.21 \times 10^{6}\left[\frac{d}{d_{32}}\right]^{3.5} e^{-16.98\left[\frac{d}{d_{32}}\right]^{0.4}} \frac{\delta d}{d_{32}}
$$

Here $n$ is the total number of droplets, $d_{32}$ is the Sauter mean diameter (SMD), and $\delta n$ is the number of droplets in the size range between $d$ and $d+\delta d$. A user-specified number of 'droplet groups' is used to represent the drop size distribution among a finite number of droplet classes.

Spray modeling for the main injection elements assumed that the fuel sheet exiting the pre-filming surface breaks up into streams of uniform liquid mass and momentum. Each annular sheet of liquid fuel was approximated as a set of 16 discrete fuel streams, located $22.5^{\circ}$ apart in the circumferential direction and $1 \mathrm{~mm}$ downstream of the trailing edge of the pre-filmer. Each stream was modeled as a $5^{\circ}$-solid cone containing spray particles injected in 8 stochastically varying directions with an SMD of $8 \mu \mathrm{m}$ with 8 droplet groups. The initial droplet injection velocity and temperature were $5 \mathrm{~m} / \mathrm{s}$ and $300 \mathrm{~K}$, respectively. The current LDI-3 'annular sheet' modeling followed the best-practices previously developed for LDI-2 airblast injectors [Ajmani 2014a] ${ }^{6}$.

Each pressure-atomizing simplex injection element (pilot) located at the center of each multi-element cup was modeled as a $60^{\circ}$ hollow cone of $10^{\circ}$ thickness. Particles were injected as 32 stochastically varying spatial streams, at an 
injection velocity of $28 \mathrm{~m} / \mathrm{s}$. Droplet size distribution was achieved using an SMD of $8 \mu \mathrm{m}$ with 8 droplet groups. The net result was that 256 new droplets were injected into the computational domain for each simplex injector (pilot) at each injection time-step of the computation.

\subsection{Chemical Kinetics Modeling}

In the current work, a 14-species, 18-reactions reduced-kinetics model was used to compute the species sourceterms for Jet-A/air combustion using finite-rate kinetics. Jet-A fuel was modeled as a surrogate mixture of decane (73\%), benzene $(18 \%)$ and hexane $(9 \%)$. The kinetics mechanism was validated by matching adiabatic flame temperature, flamespeed and ignition-delay with experimental shock-tube data and LDI-1 emissions data, in the equivalence ratio range of 0.5 to 1.0 [Ajmani 2014b] ${ }^{17}$. This reduced-kinetics mechanism was previously validated against NASA GRC's LDI-2 experimental emissions data for a second-generation, thirteen-element flametube array [Ajmani 2014a] ${ }^{6}$. Many research groups use flamelet-modeling, which allows for use of detailed kinetics models at much lower computational cost, in contrast to the reduced-kinetics approach chosen here. The current work used reduced finite-rate chemical kinetics due to enhanced robustness and accuracy experienced with OpenNCC, particularly for NOx emissions predictions of nonpremixed, liquid-fueled gas turbine engine combustor conditions.

\subsection{Turbulent-Chemistry Interaction Modeling}

A variation of the 'Eulerian PDF (EUPDF)' model of [Raju 2004] $]^{18}$ was used with OpenNCC TFNS to model the turbulence chemistry interactions. The combined TFNS/PDF approach used is similar to the FDF/PDF filtering method developed by [James 2007] ${ }^{19}$ for LES simulations. The energy and the species mass fractions over the entire computational domain are obtained by solving the time-filtered conservation equations. The EUPDF model is used as a subgrid model for mixing and combustion to provide an estimation of the filtered reaction source terms. ([Liu 2014] ${ }^{20}$ ). In practice, the OpenNCC TFNS/PDF method utilizes a hybrid algorithm. The velocity and the density are obtained by solving the TFNS equations. The energy and the species mass fractions are obtained by solving the PDF transport equation using stochastic elements (Monte Carlo particles) i.e., the filtered conservation equations for the scalars are not employed. In the current work, the PDF solver used 25 Monte-Carlo particles per computational cell at each physical time-step. In order to save computational time, a TFNS solution with laminar chemistry was first computed, and then used to advance the computations with the TFNS/PDF solver.

\subsection{THREE-CUP (NINETEEN ELEMENT) FLAMETUBE HARDWARE}

Figure 1 shows a representation of the newly designed pre-filming injector as integrated into a seven-element cup consisting of six pre-filming element (mains) and one central pilot element. Each pre-filming main injection element consist of a plain-jet orifice that injects fuel tangentially along the pre-filmer surface. Swirling airflow created by "inner" axially-bladed air-swirlers transports the fuel sheet downstream. The fuel sheet exiting the pre-filmer is broken up by the swirling airflow created by the "outer" axially bladed swirlers. The blade turning angles for the inner and outer swirlers are typically $60^{\circ}$ and $45^{\circ}$, respectively.
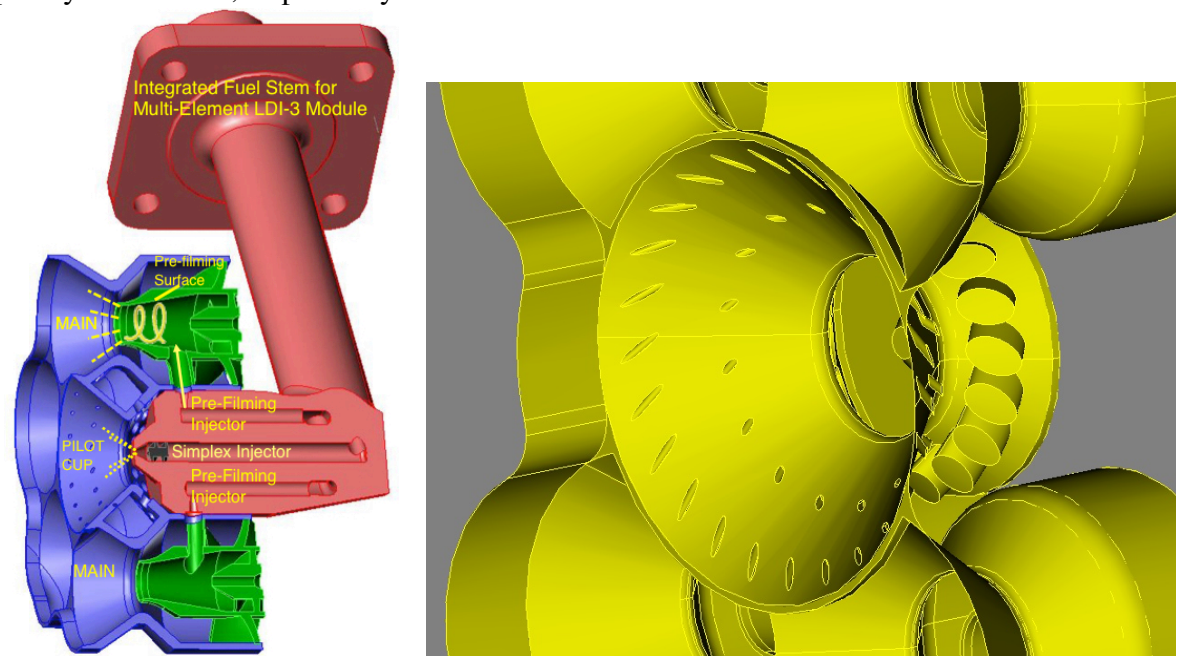

Figure 1. Dome-layout with main- and pilot-injector elements for a 7-element LDI-3 injector module (left) and details of the pilot injector with cooling holes (right) 
Some details of the pilot element, including some of the airflow passages and pilot venturi cooling holes are also shown in figure 1 (right). The pilot element is fueled by a pressure atomizer that injects fuel in the axial direction. The fuel droplets are transported and broken up by swirling airflow created by multiple plain jet orifices. These orifices are oriented at a compound angle with respect to the airflow inlet surface and their centerline is offset (typically at $45^{\circ}$ to $55^{\circ}$ ) with respect to the centerline of the pilot [Ajmani 2015] ${ }^{21}$. Integration of multiple main injection elements and a central pilot injector is used to create multi-element cups consisting of five or seven elements. An integrated fuel stem was designed by Woodward FST to simplify the fueling of multiple elements for each cup and provide potentially better thermal management of fuel for the LDI-3 designs.

Testing of the 3-cup, 19-element configuration derived from three multi-element LDI-3 modules was done in the NASA Glenn CE-5 medium pressure flametube shown in Figure 2. The flametube has a cast ceramic liner which approximates an adiabatic boundary condition. This facility can supply non-vitiated air preheated to $922 \mathrm{~K}$ at pressures up to 19.0 bar. The test rig is designed to support up to three fuel circuits.
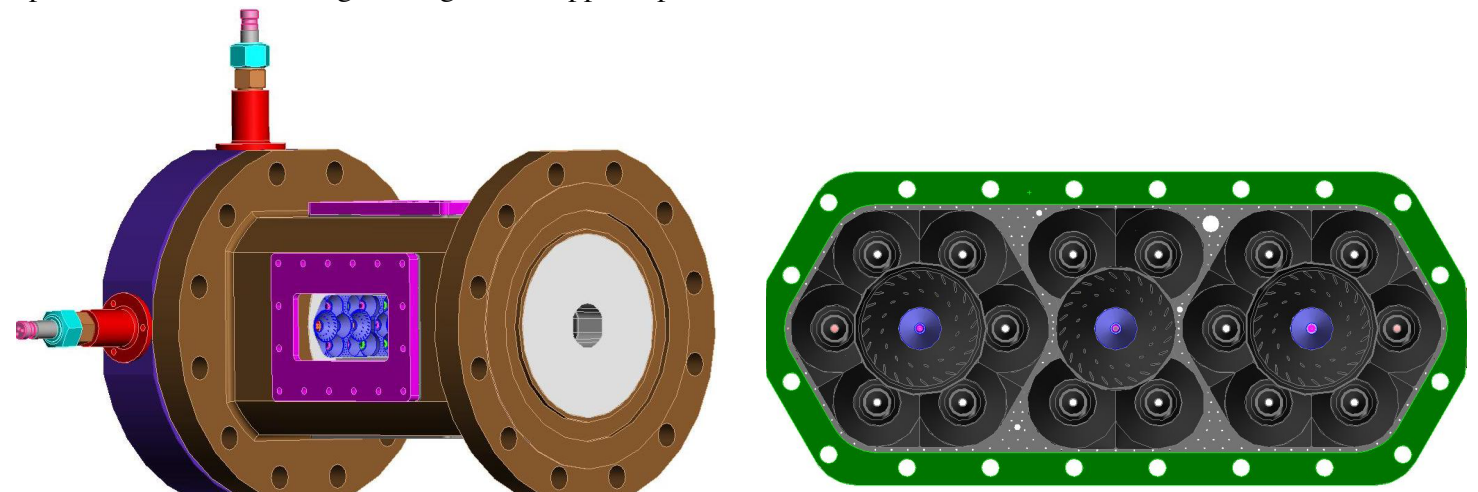

Figure 2. Dome-layout with alternating seven- and five-injector modules for an LDI-3 injector array (left) and details of the pre-filming injector (right)

Three fuel circuits were used for testing. Three different configurations were used for the fuel circuits. The first fuel circuit configuration was used for the majority of testing. In this first configuration, the first fuel circuit fed all threecenter pilot fuel-air mixers. The second circuit fed the four-main fuel-mixers on the center 5-point cup: these four fuelair mixers are called the "main 1" stage. The third fuel circuit fed all 12-main fuel-air mixers on the two outer 7-point cups. These 12 fuel-air mixers comprise the "main 2" and "main 3" fuel stages. The main 2 stages are made up of the inner three fuel-air mixers on each of the 7-point cups, for a total of six fuel-air mixers. The main 3 stages are made up of the outer three fuel-air mixers on each of the 7-point cups, again totaling six fuel-air mixers. Gaseous emissions were measured using a 5-hole probe connected to a gas bench. The probe was located 19.7-cm downstream of the combustor dome, and the 5 holes were spaced 2-cm apart. All 5 holes were on the centerline of the long axis of the combustor, and the center hole lined up with the center of the middle pilot [Tacina 2017]'.

\subsection{NASA N+3 Cycle and Experimental Data}

A generic N+3 Engine Cycle was developed at NASA for an aircraft with a takeoff operating pressure ratio (OPR) of 40 , which is $50 \%$ above the current state-of-the-art for $25 \mathrm{Klbf}$ thrust class engines. One major goal of the $\mathrm{N}+3$ development program is to reduce engine EINOx as measured at ICAO cycle points of taxi (7\% power), takeoff and descent (30\% power) by $80 \%$ as compared to CAEP6 standards for a similar thrust class aircraft. The conditions at the various cycle points of interest are shown in Table 1 . The engine inlet conditions are indicated by $\mathrm{p}_{3}$ and $\mathrm{T}_{3}$, and eng is the engine equivalence ratio.

\begin{tabular}{l|ccccr}
\hline Condition & $\begin{array}{c}\mathrm{p}_{3} \\
(\mathrm{MPa})\end{array}$ & $\begin{array}{c}\mathrm{T}_{3} \\
(\mathrm{~K})\end{array}$ & $\phi_{\text {eng }}$ & $\phi_{\mathrm{ft}}$ & $\begin{array}{r}\mathrm{T}_{\mathrm{ft}} \\
(\mathrm{K})\end{array}$ \\
\hline $7 \%$ ICAO & 0.71 & 553 & 0.103 & 0.128 & 890 \\
$30 \%$ ICAO & 1.41 & 661 & 0.186 & 0.233 & 1,231 \\
$85 \%$ ICAO & 3.28 & 835 & 0.325 & 0.402 & 1,727 \\
100\% ICAO & 3.80 & 870 & 0.354 & 0.442 & 1,832 \\
Cruise & 1.83 & 827 & 0.392 & 0.490 & 1,887 \\
Top of Climb & 1.95 & 834 & 0.377 & 0.471 & 1,858 \\
Rolling Takeoff & 4.43 & 957 & 0.446 & 0.558 & 2,107 \\
\hline
\end{tabular}

Figure 3. Operating points for a generic NASA N+3 ICAO Cycle 
Assuming $20 \%$ of air for liner cooling, the flametube equivalence ratio are given by $\phi_{\mathrm{ft}}$ and $\mathrm{T}_{\mathrm{ft}}$, respectively. All CFD computations were performed with $\mathrm{p}_{3}, \mathrm{~T}_{3}$ as inlet conditions for a flametube pressure drop of $4 \%$, and a fuel-air ratio (FAR) corresponding to the $\phi_{\mathrm{ft}}$ for the particular condition.

Figure 4 shows the experimental data for the 7\% ICAO power condition, as measured at NASA GRC's CE-5 facility. The data represents measurements with pilot-only fueling, and the local equivalence ratio for each of the three pilot elements is close to stoichiometric. The measured values of EINOx and EICO at $\phi_{\mathrm{ft}}=0.128$ (labeled $\phi_{\mathrm{ga}}$ in the figure) are in the range of $4.2-5.2 \mathrm{~g} / \mathrm{kg}$ and $51 \mathrm{~g} / \mathrm{kg}$, respectively. The measured EINOx for current LDI-3 design is higher and the EICO is lower, when compared with a previous generation (LDI-2) design at the 7\% ICAO condition.
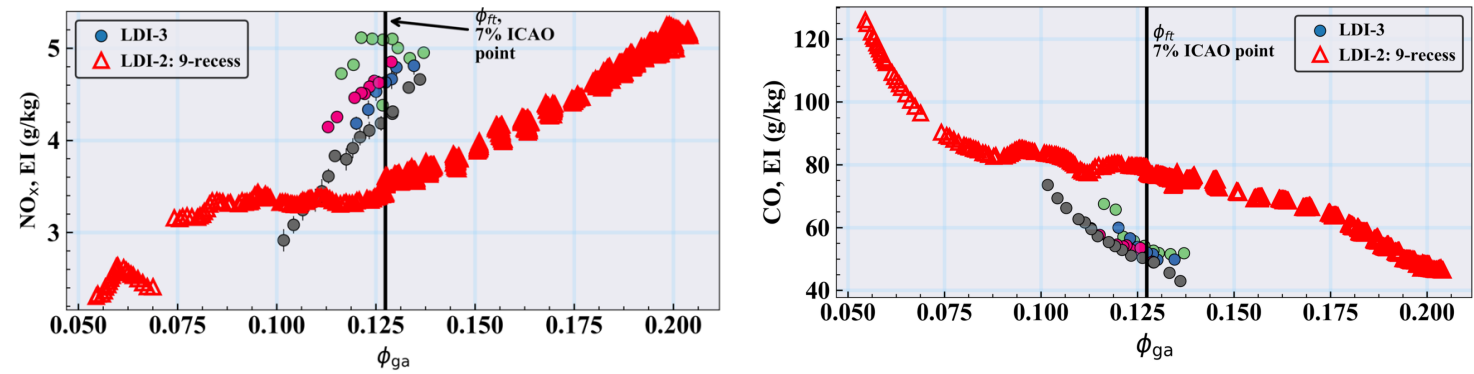

Figure 4. Dome-layout with main- and pilot-injector elements for an LDI-3 injector array (left) and details of the pilot injector with cooling holes (right) [Tacina 2017] ${ }^{9}$

Figure 5 shows the experimental data for the $30 \%$ ICAO power condition, as measured at NASA GRC's CE-5 facility. The data represents measurements with various fuel-staging schemes. The three pilots (pil) were always fueled, in combination with the four mains of the 5-element module $(\mathrm{m} 1)$, three mains from each 7-element that were immediately adjacent to the 5-element module $(\mathrm{m} 2)$, or both $\mathrm{m} 1$ and $\mathrm{m} 2$. The measured values of EINOx and EICO at $\phi_{\mathrm{ft}}=0.233(30 \%$ ICAO power condition) are $5.75 \mathrm{~g} / \mathrm{kg}$ and $50 \mathrm{~g} / \mathrm{kg}$, respectively. The CFD results reported in this paper correspond to the " $3-3.5 \%$, pil, m1" experimental condition closest to the $30 \%$ ICAO power condition $\left(\phi_{\mathrm{ft}}=0.24\right.$, $\mathrm{EINOx}=6.25, \mathrm{EICO}=50)$.
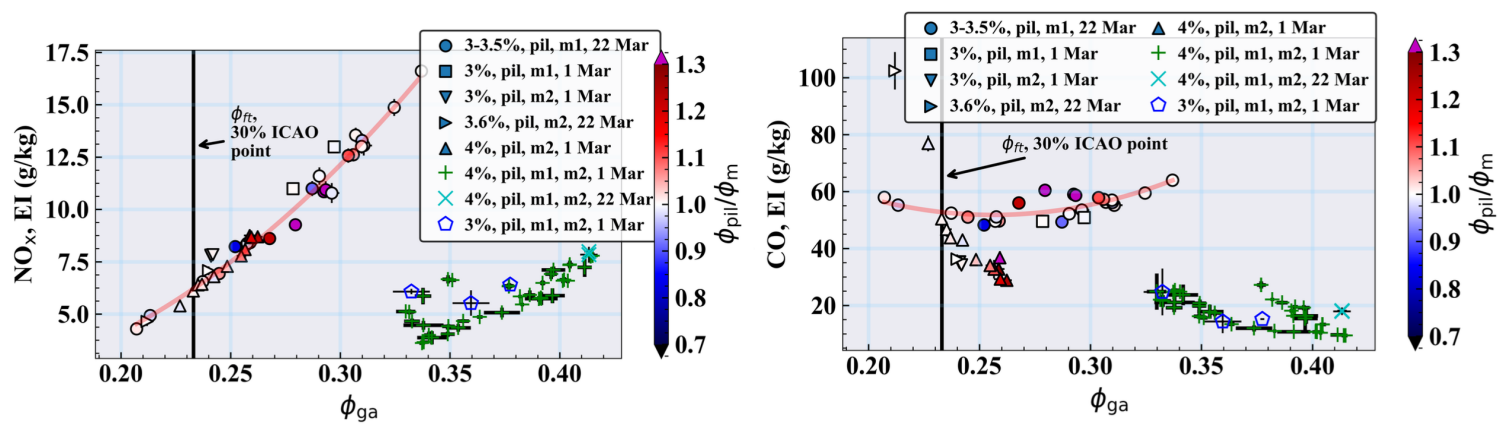

Figure 5. Dome-layout with main- and pilot-injector elements for an LDI-3 injector array (left) and details of the pilot injector with cooling holes (right) [Tacina 2017]

\subsection{THREE-CUP FLAMETUBE - OPENNCC CFD COMPUTATIONS}

This section describes OpenNCC CFD results of a nineteen element, three-module injector assembly, as tested in a flametube configuration at NASA Glenn. The three injection modules consist of a central, five-element module, with two adjacent seven-element modules, as shown in figure 6 . This configuration was selected because it is representative of a possible alternating five- and seven-element module configuration that could be used in a full annular LDI-3 combustor. The respective swirl orientation of the primary airflow through each injection element is labeled as ' $\mathrm{CW}$ ' (clockwise) and 'CCW' (counter-clockwise) when looking upstream towards the dome face. 


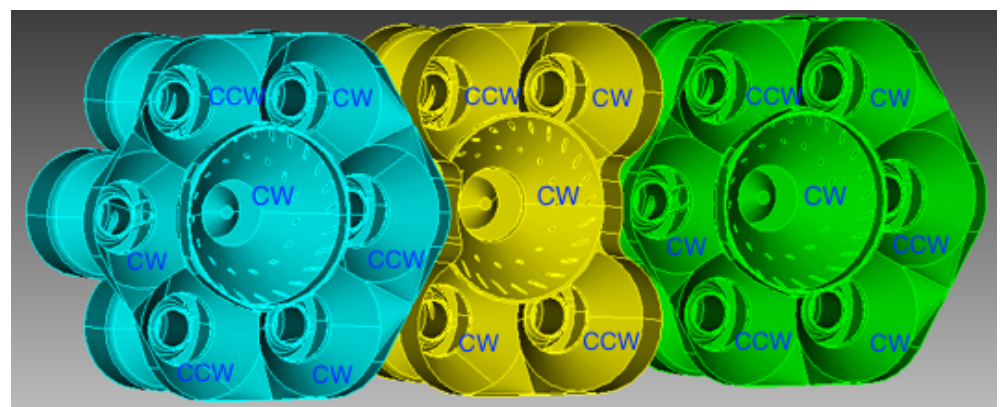

Figure 6. Dome-layout with main- and pilot-injector elements for a 3-cup LDI-3 Flametube

\subsection{OpenNCC CFD Results - 7\% ICAO Power}

This section reports the OpenNCC CFD results for the 7\% ICAO power conditions described in the previous section. Inflow boundary conditions ( specified $\mathrm{P}_{\mathrm{t}}, \mathrm{T}_{\mathrm{t}}$ ) were set corresponding to $\mathrm{P}_{3}=0.71 \mathrm{MPa}$ and $\mathrm{T}_{3}=553 \mathrm{~K}$, respectively. A pressure-specified outflow boundary condition was used. The outflow boundary back-pressure was computed from the $\mathrm{P}_{3}$ and the pressure-drop $(\Delta \mathrm{p})$. Adiabatic, no-slip boundary conditions were specified on all solid surfaces. Non-reacting RANS computations with 4-stage explicit Runge-Kutta integration were first performed, and typical convergence was obtained in 100,000 iterations using a $C F L=0.95$. The RANS solution was used to compute the effective area predicted by OpenNCC, and also used as an initial solution for the Time-Filtered Navier Stokes (TFNS) time-accurate computations.

A comparison of the computed $\mathrm{AC}_{\mathrm{d}}$ with OpenNCC RANS and TFNS with experimentally measured values of $\mathrm{AC}_{\mathrm{d}}$ is shown in Table 2. The TFNS results are based on a time-average of the final 10,000 physical time-steps of the CFD computations (10m-s of physical time). The time-averaged TFNS solution showed a slightly better prediction (than RANS) for total $A_{d}$ when compared to measured experimental data. This comparison with experimental data was used as a practical metric of "mesh quality". If the CFD prediction of $\mathrm{AC}_{\mathrm{d}}$ for a generated mesh was not within $10 \%$ of experimental data, the mesh quality was improved, and the non-reacting solutions were recomputed. The final mesh (shown in figure 7) for the current 19-element configuration that met this "mesh quality" metric consists of 21.34million all-tetrahedral elements.

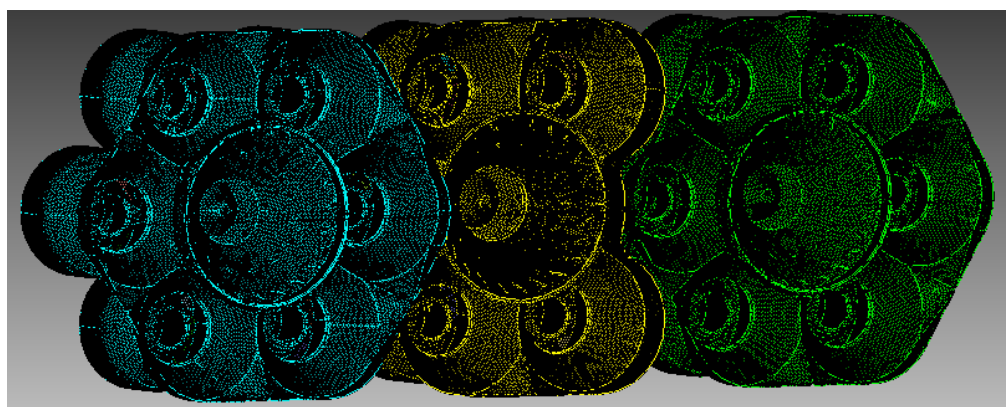

Figure 7. Surface-mesh for the 3-cup LDI-3 Flametube

Table 2. Effective area $\left(\mathrm{AC}_{\mathrm{d}}\right)$ prediction of OpenNCC RANS and TFNS compared to Experimental Data

\begin{tabular}{|c|c|c|c|}
\hline Effective Area (AC $\mathbf{d})$ & Total (in $\mathbf{2})(\%$ Error) & Mains + Cooling $\left(\mathbf{i n}^{\mathbf{2}}\right)$ & Pilot $_{\left(\mathbf{i n}^{2}\right)}$ \\
\hline Experiment & 2.6717 & 2.3613 & 0.3104 \\
\hline OpenNCC RANS & $2.8522(6.8 \%)$ & 2.5174 & 0.3348 \\
\hline OpenNCC TFNS & $2.7377(2.5 \%)$ & 2.3915 & 0.3462 \\
\hline
\end{tabular}

$\left(A C_{d}\right)_{C F D}=\frac{\dot{m}_{C F D}}{\sqrt{2 \times \rho \times \Delta P_{\text {data }}}} ;$ here $\Delta P_{\text {data }}=26882 \mathrm{~Pa}$ was used for calculating $\mathrm{AC}_{\mathrm{d}}$

The OpenNCC CFD results were post-processed to produce contour plots at several cross-sectional slices (see figure 8). The first cross-sectional slice is across the horizontal (long) axis of the flametube is designated section-AA and includes alternating main injectors and pilot injectors. Three other slices taken across the vertical (short) axis of the flametube are denoted as sections $\mathrm{BB}, \mathrm{CC}$ and $\mathrm{DD}$, one slice through each pilot element. 


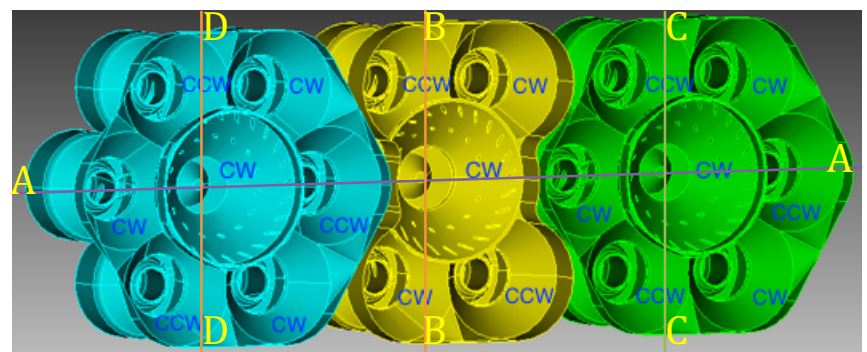

Figure 8. Cross-sectional planes for OpenNCC CFD Contours - sections AA, BB, CC and DD

Figures 9 and 10 shows the computed axial velocity contours at various cross-sections of the 19-element flametube assembly. Comparisons of the RANS and TFNS solutions show several key differences in the OpenNCC prediction of the shape, size and length of the various central recirculation zones. The predictions of the corner recirculation zones (CRZ) is also significantly different with OpenNCC TFNS. In particular, the TFNS solution predicts the presence of CRZ behind the main elements, whereas the RANS solution incorrectly predicts no CRZ (figure 9). In general, the OpenNCC TFNS solutions show consistently better symmetry across injector center lines, and similarity of strength for the recirculation zones behind each of the respective pilot and main elements. Hence, the non-reacting TFNS solution is chosen as a viable initial guess for starting the reacting flow computations.

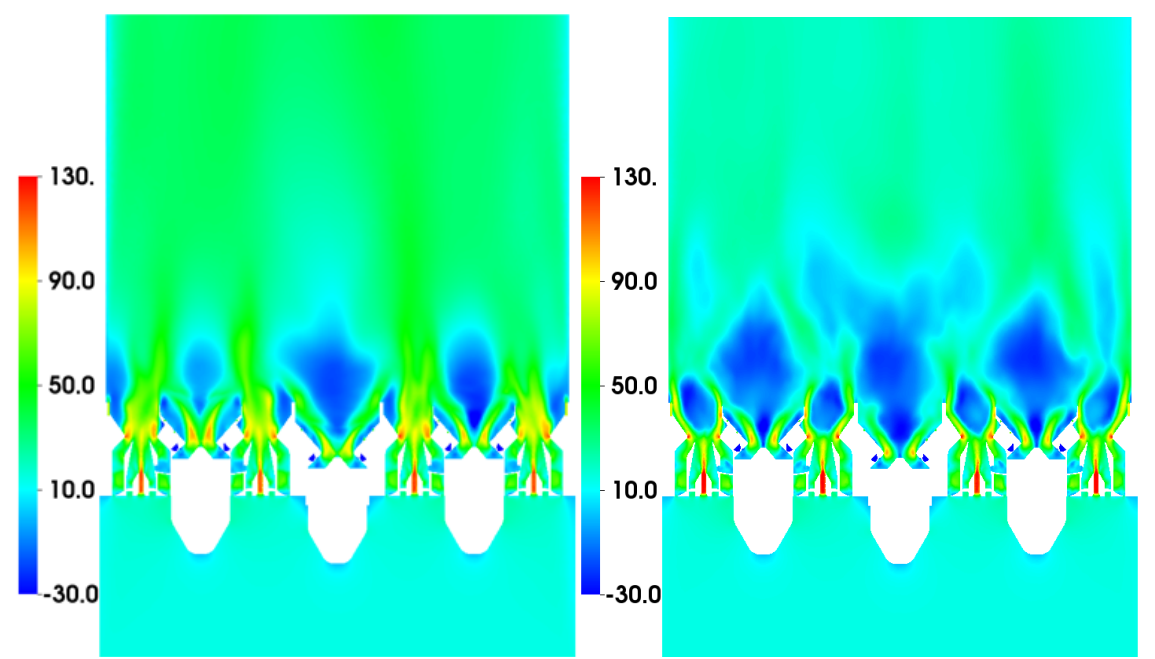

Figure 9. 7\% Power: Axial velocity (m/s) contours, non-reacting flow: RANS (left) and TFNS (right) (section AA)

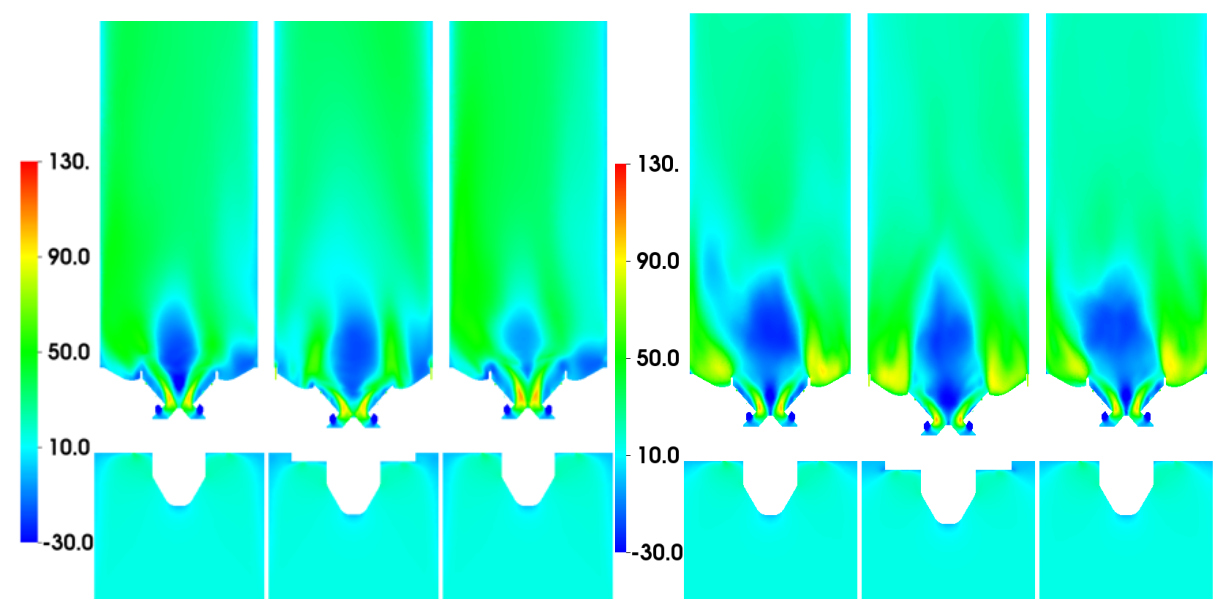

Figure 10. 7\% Power: Axial velocity (m/s) contours, non-reacting flow: RANS (left) and TFNS (right) at pilot sections $\mathrm{CC}, \mathrm{BB}$ (5-element pilot), DD (from left to right) 
Figures 11 and 12 show the computed temperature and NO contours for the 7\% ICAO power conditions. For this case, only the three pilot elements were fueled at a local equivalence ratio close to stoichiometric. The flame-structure behind the three pilots shows that the central pilot of the 5-element module is fairly well-anchored within the pilot cup. The flames behind the two pilots of the 7-element cups are lifted outside the pilot venturi, and there is very little mixing between the adjacent pilot flames for the first three or four inches downstream of the dome. The colder, heavier shear layers from the main elements have a strong "isolation" effect on the pilot flames and create significant unmixedness near the dome. This flame pattern has a significant effect on the NO production, most of which is produced 4 to 6 inches downstream of the primary flame zone. Some prompt NO is formed in the near-field immediately behind the pilot of the 5 -element cup. This is partly because of the longer-residence time produced by the slight recess ( 0.15 ") of the 5-element cup from the dome.

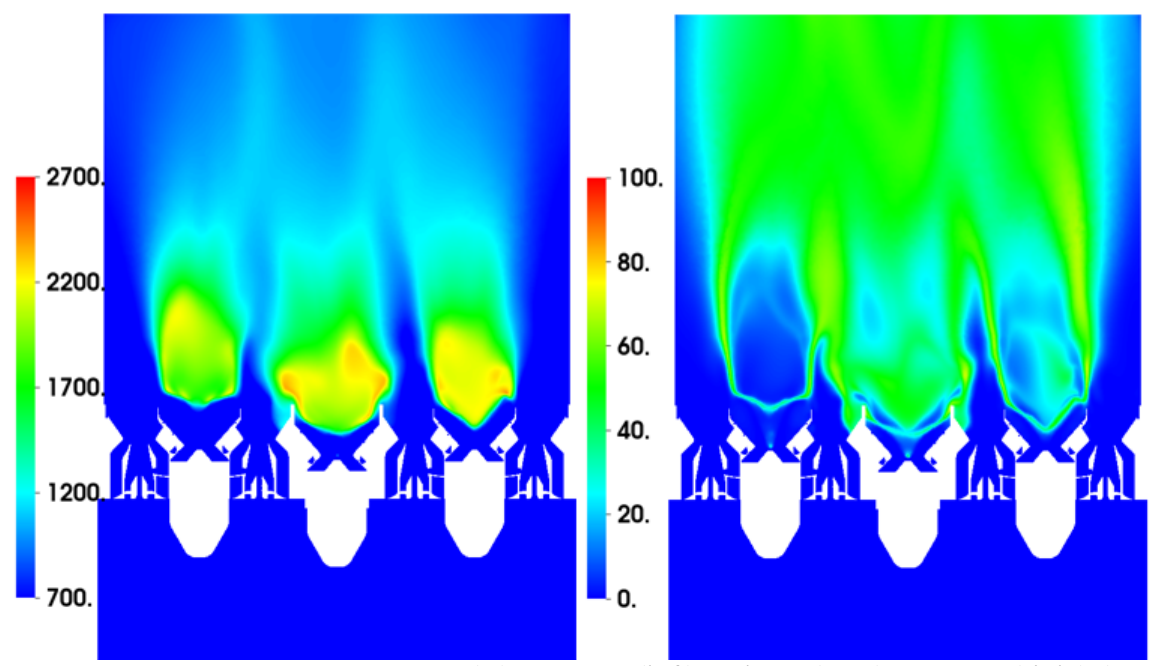

Figure 11. 7\% Power: Temperature (K) contours (left) and NO (ppm) contours (right) (section AA)
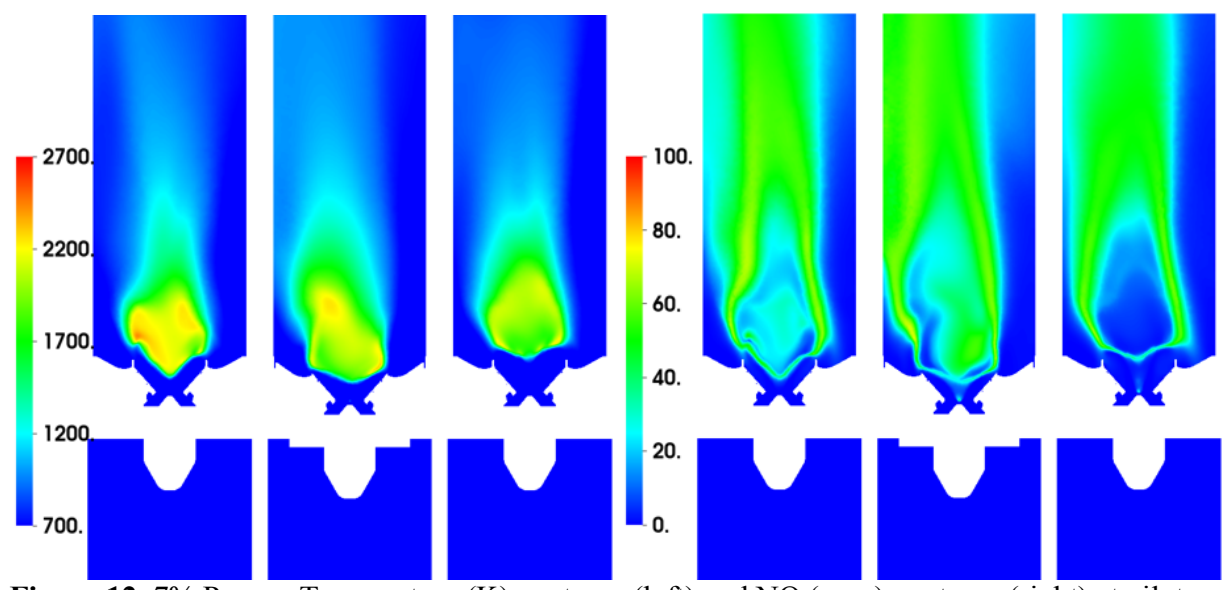

Figure 12. 7\% Power: Temperature (K) contours (left) and NO (ppm) contours (right) at pilot sections CC, BB (5element pilot), DD (from left to right)

The OpenNCC solution was post-processed to compute mass-weighted average quantities at the computational exit plane, $150 \mathrm{~mm}$ downstream of the dome). The OpenNCC predictions of $889 \mathrm{~K}\left(\mathrm{~T}_{\mathrm{ft}}\right)$ compares excellently with the experimental value of $890 \mathrm{~K}\left(\mathrm{~T}_{\mathrm{ft}}\right)$. The computed EINOx value of $4.4 \mathrm{~g} / \mathrm{kg}$ falls well within the experimental EINOx range of $4.2-5.2 \mathrm{~g} / \mathrm{kg}$. However, the computed value of $1.6 \mathrm{~g} / \mathrm{kg}$ for EICO compares poorly with the experimentally reported value of $51 \mathrm{~g} / \mathrm{kg}$. The experimental values of EICO were derived by assuming that the EICO is five times that of the measured value of unburnt hydrocarbons (UHC). A recomputation of EICO using this methodology based on EICO $\mathrm{CFD}_{\mathrm{C}}$ $=5 * \mathrm{UHC}_{\mathrm{CFD}}$ resulted in an $\mathrm{EICO}_{\mathrm{CFD}}$ prediction of 186. 


\subsection{OpenNCC CFD Results - 30\% ICAO Power}

This section reports the OpenNCC CFD results for the $30 \%$ ICAO power conditions corresponding to $\mathrm{P}_{3}=1.41 \mathrm{MPa}$, $\mathrm{T}_{3}=661 \mathrm{~K}$ and $\Delta \mathrm{p}=3.5 \%$. The differences from the $7 \%$ power case are reflected in the shorter central recirculation zones (CRZ) behind the three pilot elements, and larger corner recirculation zones on the venturi walls of the main elements, as seen in figures 13 and 14. As observed for the 7\% power case, the TFNS solution provides considerably better solution quality as compared to the RANS solution. Hence, the non-reacting TFNS solution is chosen as a viable initial guess for starting the reacting flow computations.

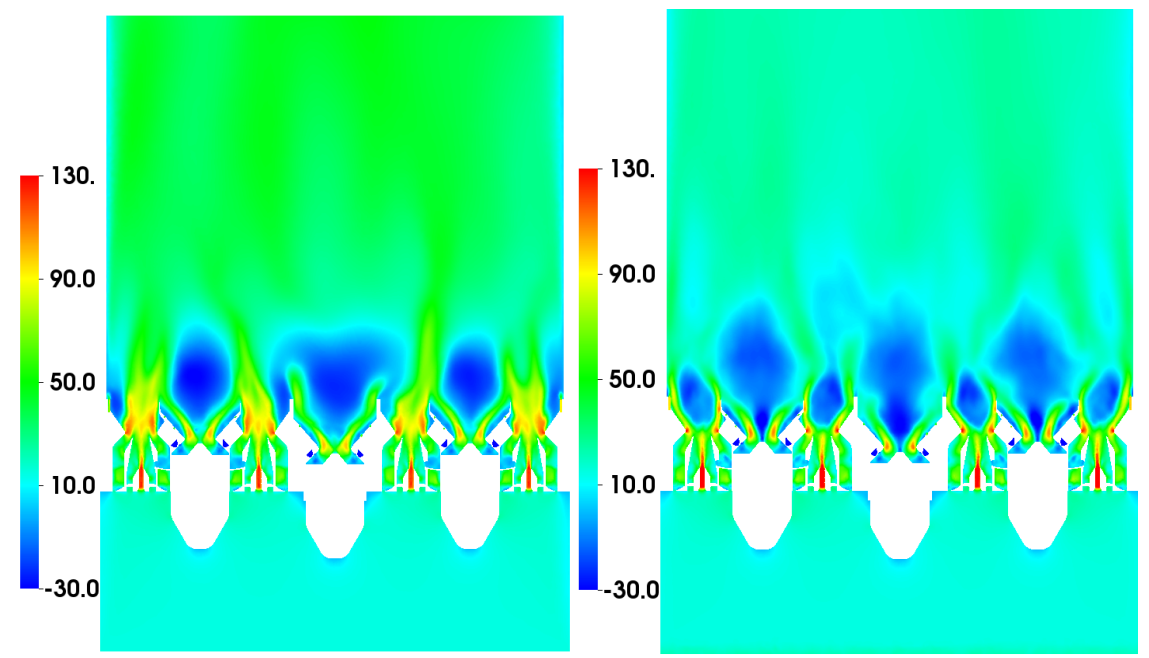

Figure 13. 30\% Power: Axial velocity (m/s) contours, non-reacting flow: RANS (left) and TFNS (right) (section AA)

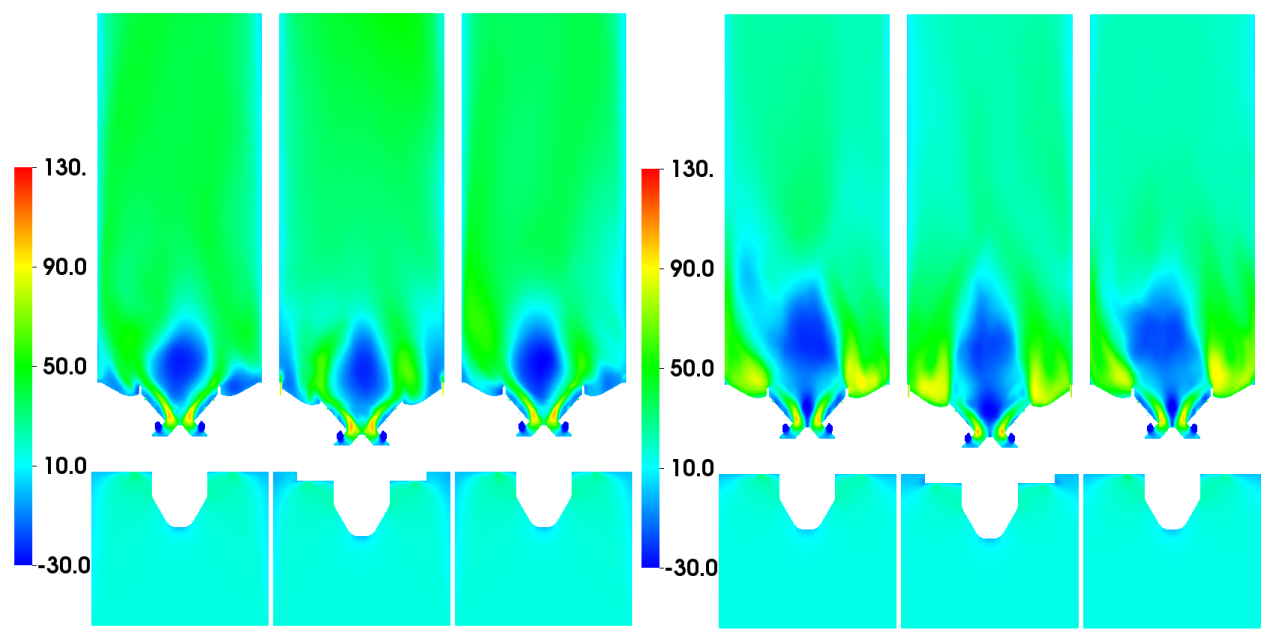

Figure 14. 30\% Power: Axial velocity $(\mathrm{m} / \mathrm{s})$ contours, non-reacting flow: RANS (left) and TFNS (right) at pilot sections $\mathrm{CC}, \mathrm{BB}$ (5-element pilot), DD (from left to right)

The reacting flow solution for the $30 \%$ ICAO power condition was computed for a global equivalence ratio, $\phi_{\mathrm{ft}}$ $=0.24\left(\mathrm{~T}_{\mathrm{ft}}=1231 \mathrm{~K}\right)$. The fuel-staging corresponding to fueling of all three pilot injectors and the four main injectors of the 5-element module was chosen. Each of the seven fueled injectors had the same local equivalence ratio. Figures 15 and 16 show the OpenNCC CFD contours for temperature and NO at various cross-sections of the 19-element flametube. The temperature contours show that the flames for all three pilots are well anchored within the venturis. The central core region of the flametube is dominated by the heat release from the fueling of all five injectors of the central five-element module. Most of the NO production is in the post-flame regions, and very little NO is produced in the vicinity of the dome. In general, the NO production is dominated by the five-element module, with marginal contributions from the two pilot injectors of the seven-element modules. 

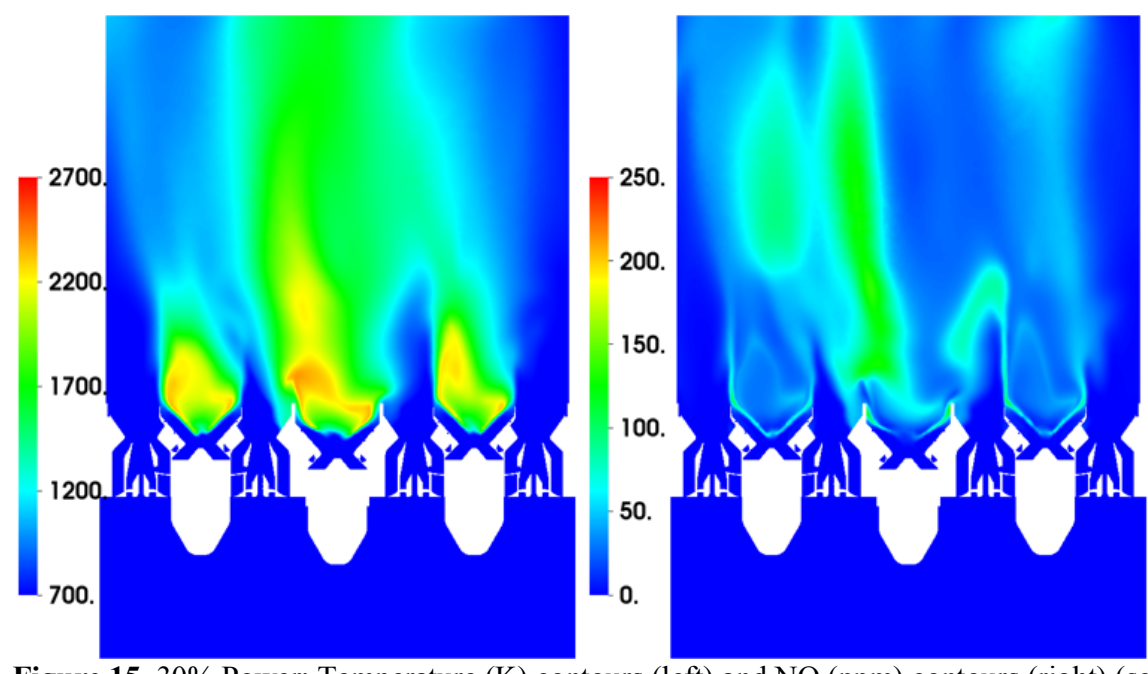

Figure 15. 30\% Power: Temperature (K) contours (left) and NO (ppm) contours (right) (section AA)
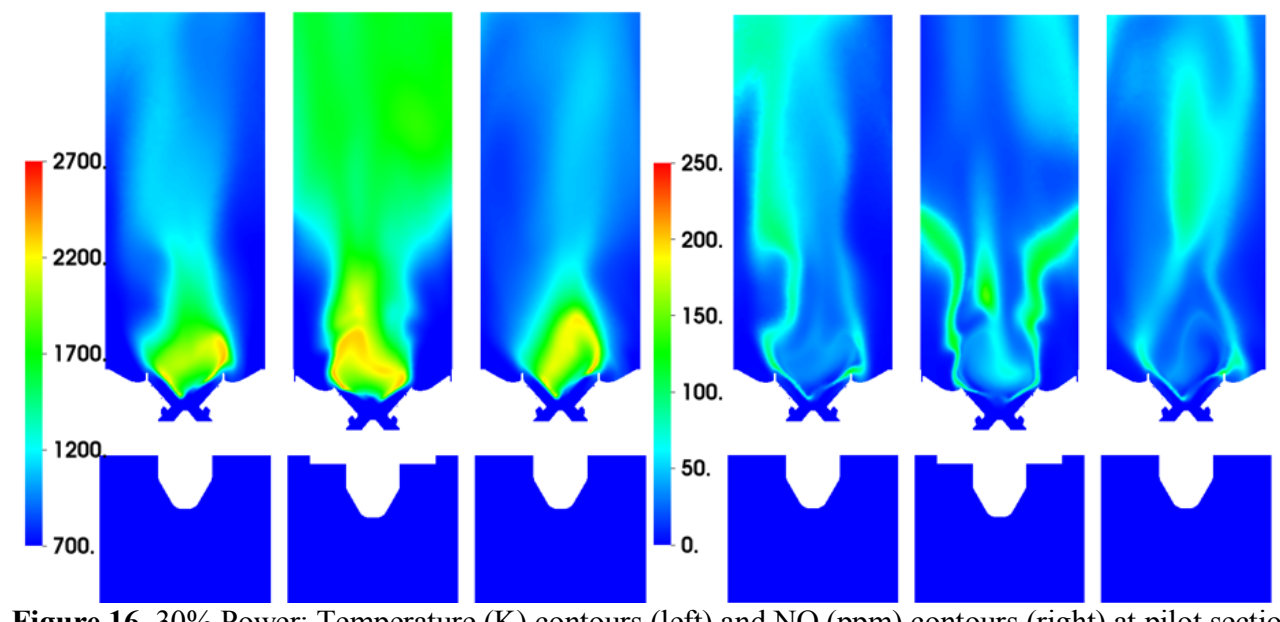

element pilot), DD (from left to right)

Cross-sectional slices at four locations downstream of the dome are shown in figure 17. These temperature contours were generated to obtain further insight into the dominant effect created by the fueling of all five injectors (four mains, one pilot) of the central five-element module in the central portion of the device. Significant unmixedness exists at the exit plane $(150 \mathrm{~mm})$, as the outer streams of cold flow are unable to mix with central hot core. This finding is significant, because the experimental measurements reported considerable differences between metered fuel-air-ratio $\left(F R_{m e t}\right)$ and the FAR measured by the gas analyzer (FAR $\left.{ }_{g a}\right)$ for this case. The CFD contours at the $150 \mathrm{~mm}$ plane show that sampling of combustion products taken by a five-hole static probe located along the centerline could experience considerable variation due to the predicted unmixedness of the flow.

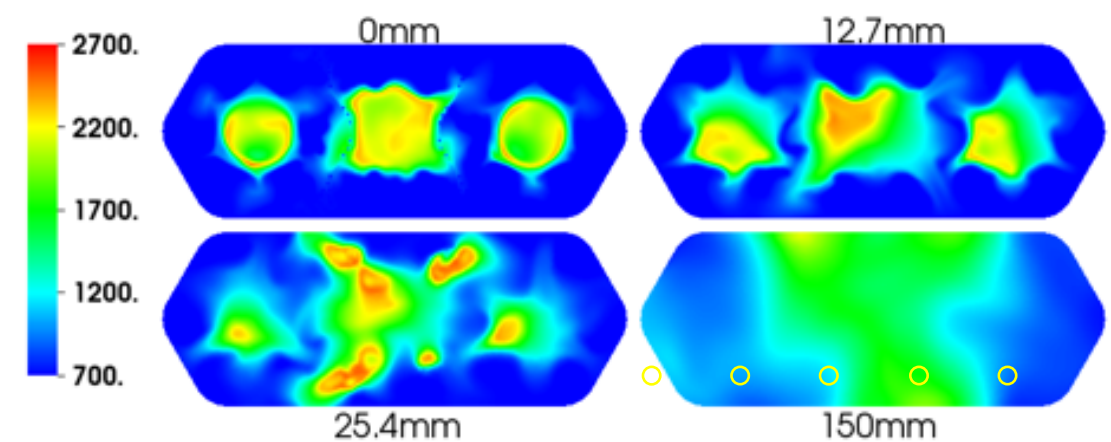

Figure 17. 30\% Power: Temperature (K) contours at four cross-sections downstream of dome. Exit-plane section $(150 \mathrm{~mm})$ shows location of experimental 5-hole static probe (circles). 
The computed spray pattern for various injectors fueled for the $30 \%$ ICAO power condition are shown in figure 18. The spray particles are colored by droplet size and overlaid on temperature contours for the entire computational domain. The three pilot elements fueled by simplex injectors exhibit very short spray cones, and most of the liquid fuel evaporates before exiting the pilot venturis. This spray pattern is consistent with the OpenNCC prediction of flame holding within each pilot venturi (figure 15). The spray pattern behind the four fueled main injectors of the central fiveelement module is completely different from the pilot injectors. The main injector fuel streams do not fully evaporate until at least an inch downstream of the dome, which also corresponds to the flame-holding region (see $25.4 \mathrm{~mm}$ location of figure 17). The CFD predictions of spray evaporation and mixing could be taken into consideration when targeting improvements in the performance of future LDI-3 injector designs.

The OpenNCC solutions were post-processed to compute mass-weighted average quantities at the computational exit plane, $150 \mathrm{~mm}$ downstream of the dome). The OpenNCC predictions of $1240 \mathrm{~K}\left(\mathrm{~T}_{\mathrm{ft}}\right)$ compares excellently with the experimental value of $1231 \mathrm{~K}\left(\mathrm{~T}_{\mathrm{ft}}\right)$. The computed EINOx value of $3.7 \mathrm{~g} / \mathrm{kg}$ is well below the experimental EINOx value of $5.7 \mathrm{~g} / \mathrm{kg}$. As discussed earlier, this discrepancy may be due to the measurement error in the experimental data due to the unmixedness across the exit plane. A computation of EICO using the methodology discussed earlier $\left(\mathrm{EICO}_{\mathrm{CFD}}=5 *\right.$ $\mathrm{UHC}_{\mathrm{CFD}}$ ) resulted in an $\mathrm{EICO}_{\mathrm{CFD}}$ prediction of 11, as compared to the experimental value of 50.

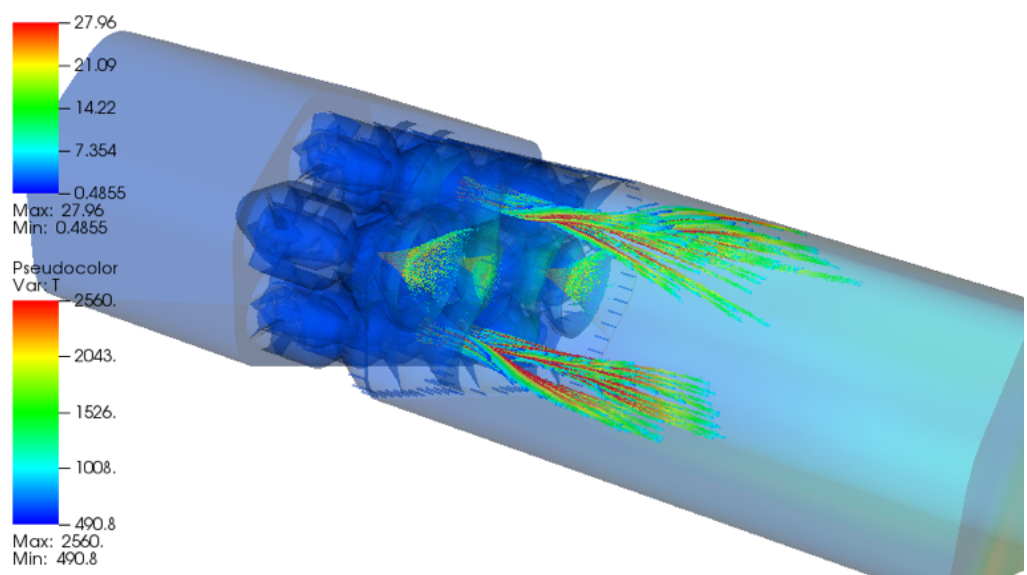

Figure 18. OpenNCC CFD prediction of spray patterns for 30\% ICAO power case; liquid droplets colored by particle size (min: $0.5 \mu \mathrm{m}, \max : 28 \mu \mathrm{m})$

\subsection{SUMMARY AND RECOMMENDATIONS}

The OpenNCC software was used to compute non-reacting and reacting flowfields for two $\mathrm{N}+3$ ICAO cycle points representing the 7\% and 30\% power conditions, respectively. A three-cup flametube with nineteen injection elements designed to meet NASA N+3 goals was chosen for the CFD analysis. Extensive experimental data obtained for this configuration was earlier reported for several N+3 cycle conditions [Tacina 2017] ${ }^{9}$. Very good agreement was observed between computed CFD EINOx and experimental data for both the power conditions chosen for analysis in this paper. Detailed analysis of CFD results revealed several useful flow diagnostics that provide guidance for future improvements of LDI-3 injector designs.

The current work has revealed some shortcomings in the ability of OpenNCC to accurately predict EICO for both of the power conditions ( $7 \%$ and $30 \%$ ICAO) of interest. One possible way to improve EICO predictions is by using a reduced finite-rate kinetics mechanism optimized for both $\mathrm{NO}$ and $\mathrm{CO}$. The reduced kinetics model used in the current work [Ajmani 2014b] ${ }^{17}$ was primarily optimized to accurately predict EINOx and $\mathrm{T}_{\mathrm{ft}}$ at relatively high-power conditions (viz. cruise and take-off). A revised reduction of the detailed chemical kinetics is recommended, with the targeted goal to accurately predict both EICO and EINOx for low power conditions. OpenNCC CFD simulations of engine condition like lean-blowout, high-altitude idle and high-altitude restart could potentially benefit from better reduced-kinetics formulations that target low-power operating conditions.

\subsection{ACKNOWLEDGEMENTS}

This work was supported by the Advanced Air Transportation Technology Project within NASA's Advanced Air Vehicles Program. 


\subsection{REFERENCES}

${ }^{1}$ A Ashcraft 2011] Ashcraft, Scott W.; Padron, Andres S.; Pascioni, Kyle A.; Stout, Gary W., Jr.; Huff, Dennis L., Review of Propulsion Technologies for N+3 Subsonic Vehicle Concepts, NASA/TM-2011-217239.

${ }^{2}$ [Hicks 2016] Hicks, Y. R. Tedder, S. A. and Anderson, R. C., Alternative Bio-Derived JP-8 Class Fuel and JP-8 Fuel: Flame Tube Combustor Test Results Compared using a GE TAPS Injector Configuration AIAA/SAE/ASEE Joint Propulsion Conference; 52nd; 25-27 Jul. 2016; Salt Lake City, UT

${ }^{3}$ [Surgenor 2016] Surgenor, A., A Path to N+3 Fuel-Flexible Combustors, Green Aviation Technical Information Meeting, March 31, 2016.

${ }^{4}$ [Ajmani 2017] Ajmani, K., Mongia, H.C. and Lee, P., "CFD Evaluation of a 3rd Generation LDI Combustor," AIAA Paper 2017-5017, 53rd AIAA Joint Propulsion Conference, July 2017, Atlanta GA.

${ }^{5}$ [Tacina 2016] Tacina, K. M., Podboy, D. P., He, Z. J., Lee, P., Dam, B. and Mongia, H., A Comparison of Three Second-generation Swirl-Venturi Lean Direct Injection Combustor Concepts, 52nd AIAA/SAE/ASEE Joint Propulsion Conference, AIAA Propulsion and Energy Forum, Salt Lake City UT (AIAA 2016-4891)

${ }^{6}$ [Ajmani 2014a] Ajmani, K., Mongia, H. C., and Lee, P., "CFD computations of emissions for LDI-2 combustors with simplex and airblast injectors", AIAA Paper 2014-3529, 50th AIAA Joint Propulsion Conference, July 2014.

${ }^{7}$ Reddy 2016] Reddy, D. R. and Lee, C-M, An Overview of Low-Emission Combustion Research at NASA Glenn, ASME Turbo Expo 2016: Turbomachinery Technical Conference and Exposition GT2016; 13-17 Jun. 2016; Seoul S. Korea; Paper GT2016-56100

${ }^{8}$ [Ajmani 2016] Ajmani, K., Mongia, H.C. and Lee, P., "CFD Based Design of a Filming Injector for N+3 Combustors,” AIAA Paper 2016-4783, 52nd AIAA Joint Propulsion Conference, July 2016, Salt Lake City, UT.

${ }^{9}$ [Tacina 2017] Tacina, K.M., Podboy, D.P., Lee, P., and Dam, B., “Gaseous Emissions Results from a Three-Cup Flametube Test of a Third-Generation Lean Direct Injection Combustor Concept”, ISABE 2017, Edinburgh UK.

${ }^{10}$ [Ajmani 2013] Ajmani, K., Mongia, H.C. and Lee, P., "CFD Best Practices to Predict NOx, CO and Lean Blowout for Combustor Design,” ASME IGTI Paper GT2013-95669, ASME Turbo Expo 2013, San Antonio TX, June 2013.

${ }^{11}$ [Tacina 2005] Tacina, R., Lee, P., and Wey, C., "A Lean-Direct-Injection Combustor Using a 9 Point Swirl-Venturi Fuel Injector," ISABE 2005-1106.

${ }^{12}$ [Swanson 1997] Swanson, R.C., and Turkel, E., "Multistage Schemes with Multigrid for Euler and Navier-Stokes Equations," NASA TP-3631, 1997.

${ }^{13}$ [Shih 1998] Shih, T.-H., Chen, K.-H., Liu, N.-S., Lumley, J. L., "Modeling of Turbulent Swirling Flows," NASA-TM 1998-113112.

${ }^{14}[$ Shih 2000] Shih, T.-H., Povinelli, L.A., Liu, N.-S and Chen, K.-H., "Generalized Wall Function for Complex Turbulent Flows," NASA TM 2000-209936.

${ }^{17}$ [Ajmani 2014b] Ajani, K., Kundu, K., and Yungster, S., "Evaluation of Reduced Mechanisms for Combustion of JetA in LDI Combustor CFD Calculations," AIAA Paper 2014-3662, AIAA Propulsion and Energy Conference,

Cleveland, OH, July 2014.

${ }^{15}$ [Liu 2011] Liu, N.-S., Shih, T.-H. and Wey, C.T., "Numerical Simulations of Two-Phase Reacting Flow in a SingleElement Lean Direct Injection (LDI) Combustor Using NCC,” NASA/TM-2011-217031.

${ }^{16}$ [Raju 2012] Raju, M. S., “LSPRAY-IV: A Lagrangian Spray Module,” NASA CR-2012-217294. 
${ }^{18}$ [Raju, 2004] Raju, M.S., "Current Status of the Overall Spray Solution Procedure (Combined CFD/Scalar-MonteCarlo-PDF/Spray Computations) Developed under NCC," AIAA Paper 2004-0327, 42nd AIAA Aerospace Sciences Meeting and Exhibit, January 2004, Reno, NV

${ }^{19}$ [James, 2007] James, S., Zhu, J. and Anand, M.S., "Large Eddy Simulations of Turbulent Flames Using the Filtered Density Function Model," Proceedings of the Combustion Institute 31 (2007) 1737-1745.

${ }^{20}$ [Liu 2014] Liu, N.-S., and Wey, C.T., "On the TFNS Subgrid Models for Liquid-Fueled Turbulent Combustion,” AIAA Paper 2014-3569, AIAA Propulsion and Energy Conference, Cleveland, OH, July 2014.

${ }^{21}$ [Ajmani 2015] Ajmani, K., Mongia, H.C. and Lee, P., "Parametric Design of Injectors for LDI-3 Combustors," AIAA Paper 2015-3785, 51st AIAA Joint Propulsion Conference, July 2015, Orlando, FL. 